\title{
Design of Intelligent Water-Supply and Temperature Control System Based on Hot Water Box
}

\author{
Hong-Jun GUa, Ji LI, Shi-Jun LI ${ }^{b}$, He GONG, Jian LI, Yong-Chen LUO \\ Jilin Agricultural University, Changchun 130118, Jilin, China \\ aghj_dennis@163.com, IIsj0883@sina.com
}

Keywords: hot water box, water-supply, temperature-control, SCM.

\begin{abstract}
This paper uses SCM as the control core to design an intelligent water-supply and temperature control system based on hot water box, which is suitable for the countryside and the edge of the town in summer. This system can solve the problems of water supply and controlling the water temperature for the outdoor bath, and which has the obvious advantages of energy conservation and environment protection, safe and reliable operation, low cost, and applicable functions. The SCM can collect the water temperature in real time from the sensor DS18B20, and water volume from the water level sensor. According to the water temperature and volume in the box, SCM controls the small pump to supply water into the box. The user can set the time of bath through the keyboard. The clock chip DS1302 provides the date and time. The power adopts the green energy of solar panel with $5 \mathrm{~V}$ and $24 \mathrm{~V}$. The design provides the convenience for the peasants, especially for the family with only children and the aged. This system has a certain significance for the science and technology popularity in the countryside.
\end{abstract}

\section{Introduction}

In summer, hot water box with low cost and convenience is very popular for bath in the rural areas. Hot water box is placed on the roof and cool water is poured into it. The strong sunlight can heat the water for bath or washing clothes. However, the roof is so high that rural people supply water in the box by climbing the ladder, which is dangerous, especially for the aged and boy. In addition, the water in the box is too hot at noon, and becomes too cool after pouring much water. So peasants often bath after sunset, which limits the bathing time.

There are some related researches about the hot water box. The grey-box model of a domestic hot water electric boiler is presented [1]. The home-use hot water system is studied to save energy and water in supplement of home-use hot water by means of installing backwater pipeline in parallel with the main hot water pipeline, as well as making use of single-chip computer to realize automatic control and certain intelligent control of home-use hot water supply system [2]. In view of the problems facing with the artificial controlled hot water heating in the greenhouse, a temperature control system for hot water heating based on single-chip microcomputer is designed [3]. A 3-dimensional mathematical model of the hot water tank with two water inlets and internal heat source was built [4]. The thermal performance of solar hot water system with novel water tank is studied, which shows that the average thermal loss coefficient is reduced by $1.35-3.42 \mathrm{~W} /\left(\mathrm{m}^{2} \cdot \mathrm{K}\right)$, and the average daily efficiency is increased by $2.37 \%-4.02 \%$ [5]. The author studies the improved thermal stratification with obstacles placed inside the vertical mantled hot water tanks [6].

The micro-controller STC89C52 is adopted as the core to design an intelligent water-supply and temperature control system based on hot water box. This system can automatically detect the water temperature and volume, and supply the cool water to control the water temperature automatically. This design solves the inconvenience in the process of bath for peasants in the countryside.

\section{Overall System Framework}

This system includes micro-controller STC89C52, DS1302 clock module, DS18B20 temperature sensor, keyboard, displaying screen, solid state relay and small pump. The overall system framework is shown in Fig. 1. 
The micro-controller can collect the signals of water temperature and water level from the corresponding sensors, which decides whether pump works to carry water into the box. Half of the box is filled with water when no one baths. DS1302 clock module can provide the time and date information. The user can set the time carrying water time via keyboard and displaying screen can show the current time, the time of bath, water level and temperature.

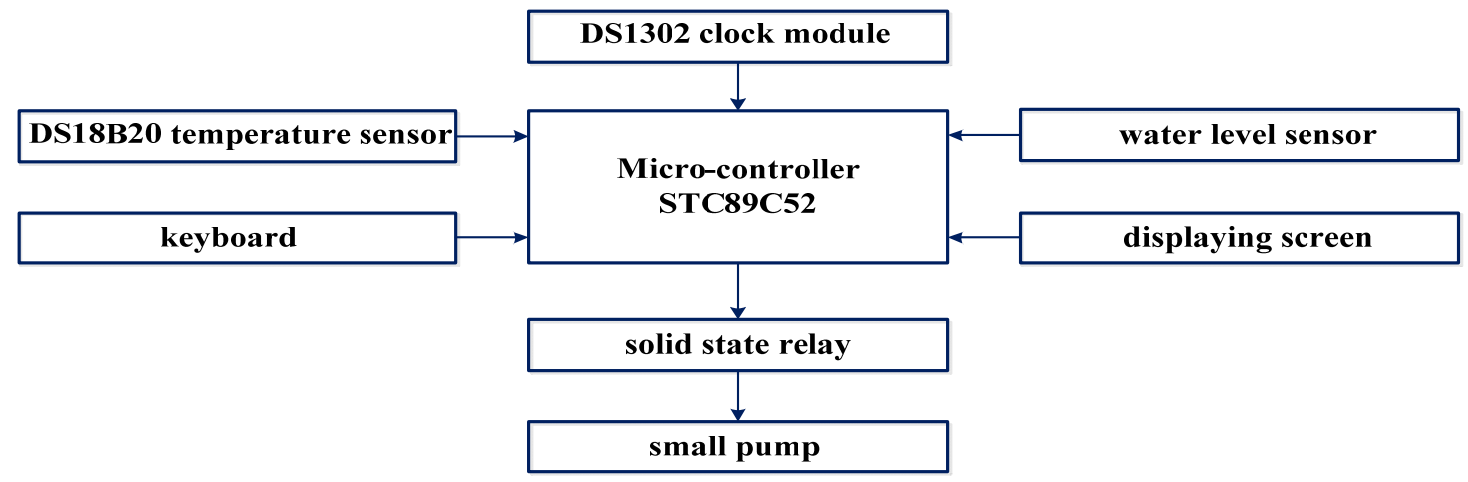

Fig. 1 The overall system framework

\section{System Hardware Design}

The interface design of SCM is shown in Fig .2, including reset circuit and clock circuit. LCD12864 is used as the displaying screen in Fig .3. The interfaces data0-data7 transfer data ( $\mathrm{RS}=$ '1') or commands ( $\mathrm{RS}=$ '0') from SCM to LCD12864. The port $\mathrm{RW}=$ '1' and '0' represents reading and writing data respectively. When the port $\mathrm{E}\left(\mathrm{RW}={ }^{\prime} 0^{\prime}\right)$ gets falling edges, the data or commands can be written in the LCD12864.
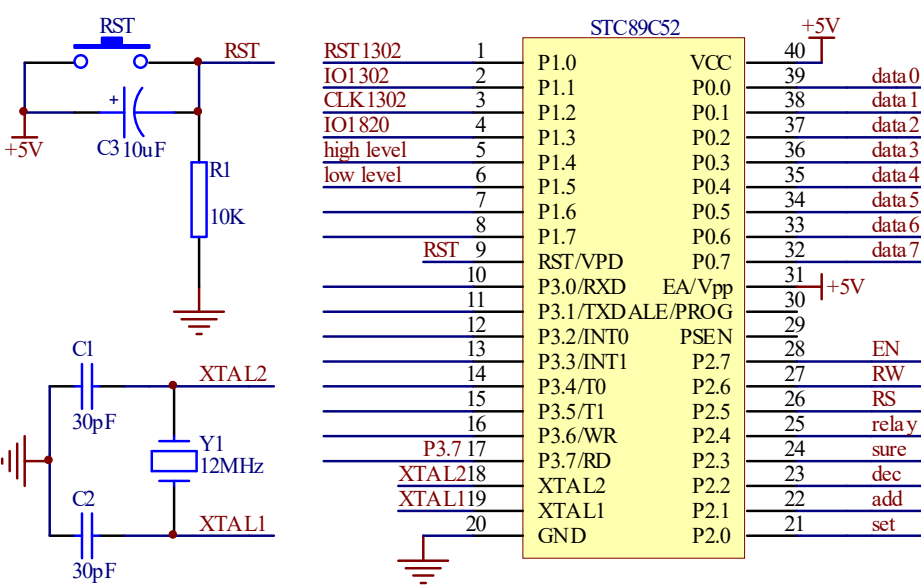

Fig. 2 The interface design of SCM

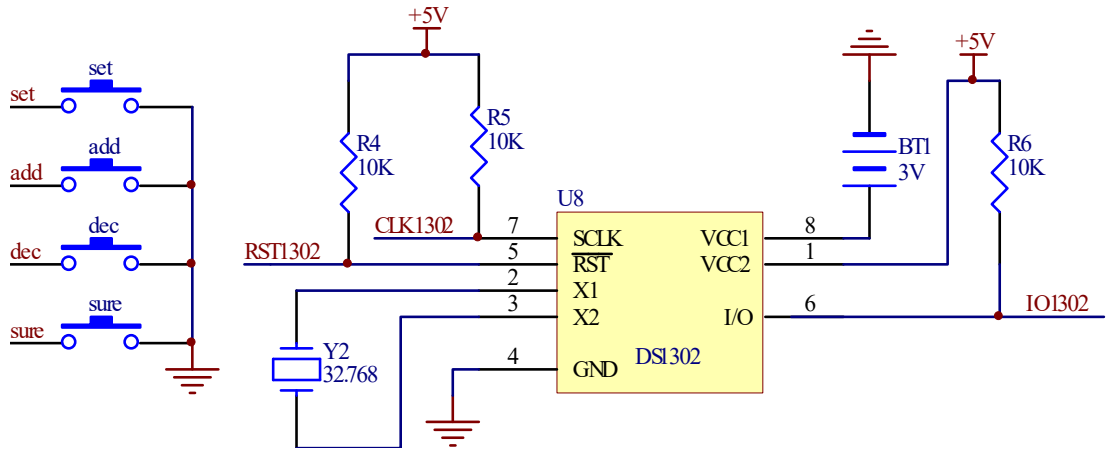

Fig. 4 The interface design of keyboard and DS1302

As shown in Fig .4, the keyboard has 4 keys: 'set', 'add', 'dec' and 'sure', which can adjust the current time, date and year, and set the bath time and suitable water temperature. The clock module 
DS1302 with a button battery ( 3V backup power ) is connected with SCM by the ports: 'RST1302', 'CLK1302', and 'IO1302', and the corresponding information can be read or written by SCM.
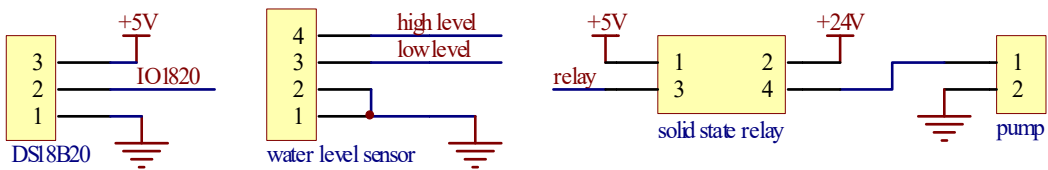

Fig. 5 The interface design of sensors, relay and pump

As shown in Fig .5, the interface circuits of DS18B20, water level sensor, solid state relay and pump are designed. DS18B20 adopts digital single bus technique to communicate with SCM via the port 'IO1820'. SCM can acquire the water volume from the ports 'lowlevel' and 'highlevel' of water level sensor roughly. And SCM can give ' 0 ' or ' 1 ' to control solid state relay, which lets the small pump draw water or stop working.

Fig .6 shows the pictures of control circuit and hot water box.

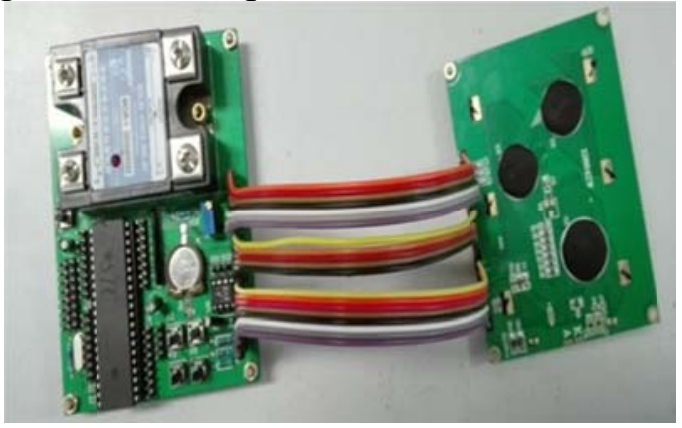

(a)

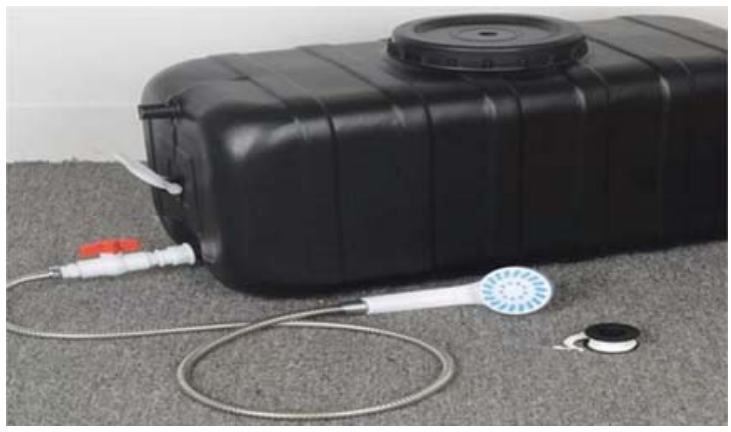

(b)

Fig. 6 The pictures of (a) control circuit and (b) hot water box

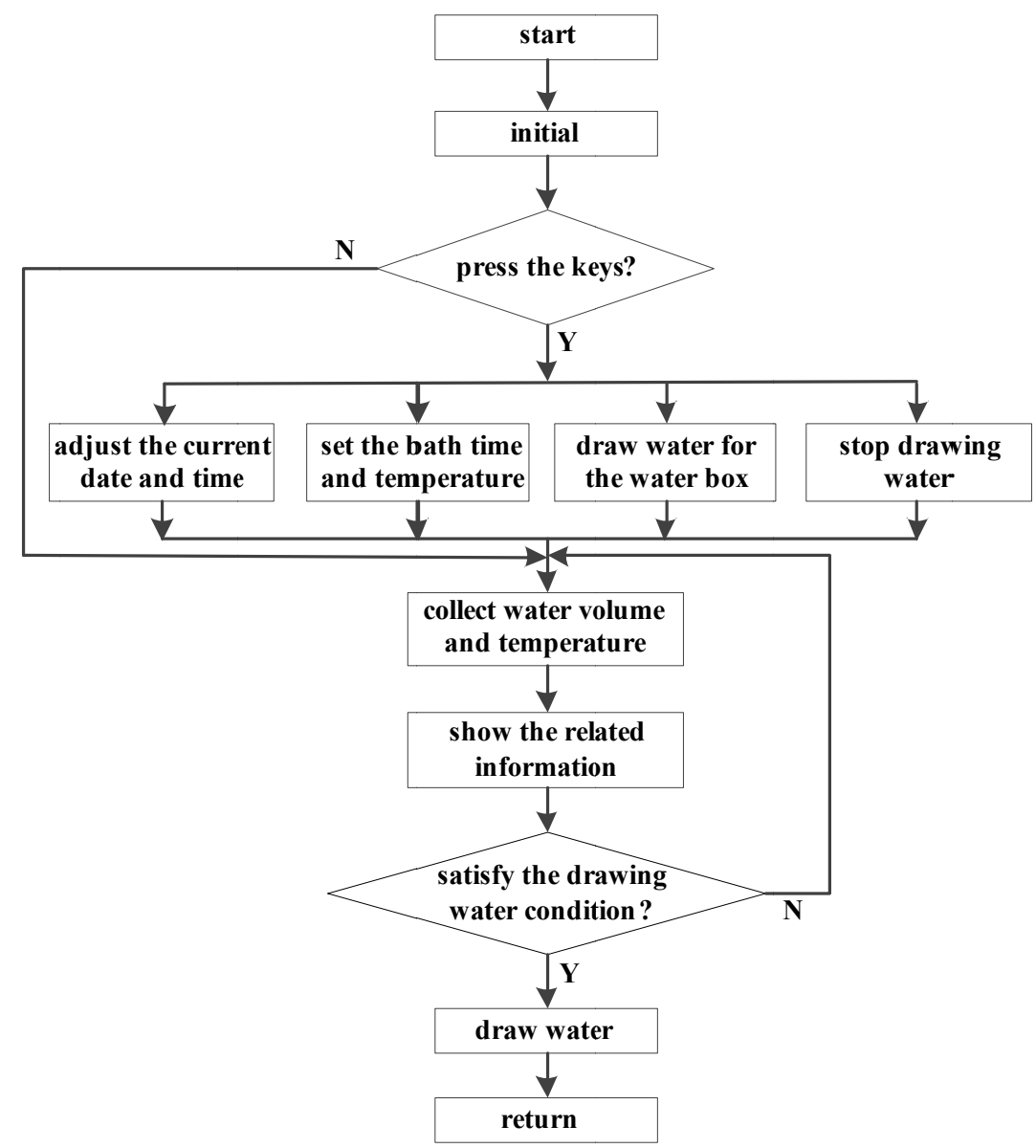

Fig. 7 The system program flow chart 


\section{Program flow chart design}

Fig .7 shows the system program flow chart. Firstly, the system mainly does the initial operations on LCD12864, DS1302 and DS18B20. Secondly, the user may adjust the current date and time, set the bath time, draw water for the water box and stop drawing water via the keyboard. Thirdly, water level and temperature can be collected and displayed. Fourthly, the system judges whether drawing condition is satisfied. If satisfied, SCM controls the pump to draw water. Lastly, the main function returns. The flow charts of DS1302, DS18B20 and LCD12864 are well-known, which are omitted.

\section{Conclusions}

This paper designs an intelligent water-supply and temperature control system based on hot water box and gives overall framework, hardware schematic diagrams and program flow chart. The system can draw water to adjust the water temperature and level by gaining the data from sensors. The hardware and software adopts modular design, which provides convenience for future maintenance and upgrades. This paper can play an important role for outdoor bath in the rural area and the edge of the town.

\section{Acknowledgments}

Ji LI is the corresponding author of this paper. The authors wish to express their gratitude to the projects: Design of Standardized Breeding System for Rabbits Based on IOT, Deer Breeding Intelligent Monitoring and Controlling System Based on RFID of IOT, from Education Department of Jilin Province, Jilin Province Economic Structural Adjustment Leading Fund Special Project (No. 2014Y108) and Changchun City Science and Technology Plan Project (No. 14nk029, No. 13KG71), Key Tackling Item of Jilin Province Science \& Technology Department (No. 20140204045NY), Jilin Province Science \& Technology Department Project (No. 20150204058NY, No. $20140204045 \mathrm{NY}$ ) for their generous support of this work.

\section{References}

[1] Abdul Atisam Farooq, Abdul Afram, and Nicola Schulz, et al. Grey-box modeling of a low pressure electric boiler for domestic hot water system [J]. Applied Thermal Engineering, 84(2015) 257-267, in English.

[2] ZHANG Ao. Energy Saving Control in the Home-use Hot Water System by Single-chip Computer [D]. Wuhan: Wuhan Institute of Technology, 2011, in Chinese.

[3] YAN Cong, LUO Xiao-Lin, and LI Jie. Design of Hot Water Heating System Based on Single-chip Control in the Greenhouse [J]. Anhui: Journal of Agricultural Science, 2009, 37(2): 899-900, in Chinese.

[4] Qiu Bu, and Zhang Xiao-Song. Simulation Investigation of Mixing Process of Hot Water Storage Tank with Internal Heat Source [J]. Beijing: Acta Energiae Solaris Sinica, 2013, 34(10): 1795-1801, in Chinese.

[5] Liao Cheng-Jun, Wang Jin-Fu, and Yang Wen, et al. Study of Thermal Performance of Novel Heat Storage Water Tank[J]. Beijing: Acta Energiae Solaris Sinica, 2014, 35(12): 2504-2507, in Chinese.

[6] Dogan Erdemir, Necdet Altuntop. Improved thermal stratification with obstacles placed inside the vertical mantled hot water tanks [J]. Applied Thermal Engineering, 100(2016) 20-29, in English. 